\title{
POSTOPERATIVE PAIN EVALUATION OF MINERAL TRIOXIDE AGGREGATE AND PROPOLIS AFTER PULPOTOMYIN CARIOUS PRIMARY MOLARS: A RANDOMIZED CONTROLLED TRIAL
}

\author{
Rawda Nader Fathy*, Adel El Bardissy**, \\ Fatma Abdelgawad $^{* * *}$ and Ahmed M. Abd Alsamad ${ }^{* * * *}$
}

\section{ABSTRACT}

Aim: The aim of this study is to evaluate the postoperative pain of mineral trioxide aggregate (MTA) and propolis after pulpotomy in carious lower primary molars.

Methodology: 28 Healthy children aging 5-8 years old with at least one carious primary molar at each side. Each child received MTA in right or left side and Propolis in the other side. Clinical follow up was done at 3,6, and 9 months. Radiographic follow up was done at 6 and 9 months.

Results: All cases were free of pain along the follow up period except one case in propolis group showed pain after 6 months then disappeared at 9 months. Sinus tract appeared in $3.85 \%$ in propolis group at 6 months and $4 \%$ in both groups at 9 months. Regarding periapical radiolucency, in MTA group, 3 cases (11.54\%) were affected after 6 months and 4 cases (16\%) after 9 months. In propolis, $4(15.38 \%)$ of cases were affected after 6 months, and $6(24 \%)$ of cases after 9 months. Furcation Involvement, appeared in MTA group, in 2 (7.69\%) cases were affected after 6 months. While in propolis group, $6(23.08 \%)$ cases were affected after 6 months.

Conclusions: The clinical outcome of propolis is comparable to that of MTA at both 6 and 9 months follow up period. On the other hand, MTA showed better results in all radiographic outcomes when compared to propolis.

KEYWORDS: Propolis; Mineral trioxide aggregate; Pulpotomy; Vital pulp therapy.

\footnotetext{
* Dentist in Egyptian Ministry of Health, Egypt

** Professor of Pediatric Dentistry and Dental Public Health Department, Faculty of Dentistry, Cairo University *** Associate Professor in Pediatric Dentistry and Dental Public Health Department, Faculty of Dentistry, Cairo University **** Associate Professor in Oral and Maxillofacial Radiology Department, Faculty of Dentistry, Cairo University
} 


\section{INTRODUCTION}

Dental caries is the most common chronic disease of childhood. It presents a significant clinical problem in primary teeth. If left untreated; caries progression can approximate the dental pulp, endangering the vitality of the tooth and causing infection, abscess, and premature tooth loss. Thus, choosing the best material to restore the pulp of primary teeth remains the most common problem ${ }^{[1]}$. There are several methods to preserve pulp vitality in carious teeth. Pulpotomy is vital pulp therapy for primary teeth in which the coronal pulp tissue is surgically removed and a suitable material is placed on the remaining radicular pulp to protect it from further injury. Pulpotomy is applicable only when the inflammation of the pulp is limited to the coronal tissue and the remaining pulp is vital. Various pulpotomy medicaments aiming at devitalization, preservation, or regeneration of the remaining pulp tissue have been used until today ${ }^{[2]}$.

The ideal pulpotomy material should leave healthy and vital radicular pulp which is completely enclosed within an odontoblast-lined dentin chamber. So, the tissue would be isolated from restorative materials in the chamber, and the chances of internal resorption will decrease. The odontoclasts of an uninflamed pulp could enter and remain in a physiologic manner. Unlike the other two categories for pulp treatment, the reason for the developing field of regeneration is actually based on sound, and biologic principles ${ }^{[3]}$.

Studies have shown the use of MTA in direct pulp capping and pulpotomies in vital, immature permanent teeth which are absent of signs or symptoms of irreversible pulpitis as well as for pulpotomy treatment of primary teeth to induce dentin bridge formation ${ }^{[4-7]}$. Despite MTA advantages, it has some disadvantages that include the high solubility, presence of toxic elements in the material composition, higher cytotoxicity in its freshly mixed state, high $\mathrm{pH}$ during setting, difficult handling characteristics, long setting time, high price, and discoloring effect of both gray and white form ${ }^{[8]}$.

Hence, the need arises to discover a pulpotomy agent that potentiates the natural pulp healing process, biocompatible and cost-effective. Some natural materials from the field of traditional medicine have also been introduced as medicaments in vital pulp therapy as an alternative to commercially available artificial products. Propolis, a resinous substance collected from trees and shrubs by honey bees is known for its claimed beneficial effects on human health, it is now used as a dietary supplement and has also gained popularity in dentistry as an intracanal medicament, as a cariostatic agent, for storage of avulsed teeth and also as a root canal irrigate due to its known anti-inflammatory and immunomodulating properties ${ }^{[9}$.

There are no sufficient clinical studies done on propolis. This study conducted to examine the success of vital pulpotomy using natural material on primary teeth. Propolis is introduced as natural medicaments in vital pulp therapy and as an alternative to commercially available artificial products like formocersol. The aim of this study was to evaluate the postoperative pain of mineral trioxide aggregate and propolis after pulpotomy in carious primary molars.

\section{PARTICIPANTS AND METHODS}

The procedures were carried out in the postgraduate clinic of Pediatric Dentistry and Dental Public Health Department- Faculty of Dentistry, Cairo University, Egypt. The clinical procedure and associated risks and benefits were fully explained to the parents or legal guardian of the participants. Written informed consent were obtained from the parents or legal guardian of the participants prior to investigation. All participants were screened by taking a detailed history and performing a thorough clinical and radiographical examination. This research was approved by Research Ethics Committee, Faculty of Dentistry, Cairo University, Egypt (Appendix 1). 
Twenty-eight children were randomly selected with age range 5-8 years old, each have at least one carious primary molar tooth at each side of their mouth. Computer sequence generated random numbers was used. Randomization was done online by using computer software www.random.com .The sequence generated 2 codes (A \& B). Each code stands for either intervention or control.

Sample size calculation was based on a previous study by Shafie et al. ${ }^{[5]}$ the difference in pain score between the groups is $1 \pm 1.1$. Using the power of $80 \%$ and $5 \%$ significance level we will need to study 20 children in each group. This number increased to a sample size of 23 children to adjust for using a nonparametric test. The number was increased again a total sample size of 28 children to compensate for losses during follow up (25\% more than the calculated). Sample size calculation was achieved using PS: Power and Sample Size Calculation software Version 3.1.2 (Vanderbilt University, Nashville, Tennessee, USA) (Appendix 2).

The children were selected that fulfilled the following inclusion criteria: Cooperative patient, 5-8 years old patient with at least one carious primary molar tooth at each side of the patient's mouth, Presence of at least two-thirds of the root length radiographically, restorable tooth, and the final selection for inclusion in the study was done intraoperatively, only when hemostasis was adequately achieved within 5 minutes after coronal pulp amputation. The exclusion criteria were as follows: history of systemic diseases; teeth showing clinical and radiographical evidence of pulp degeneration such as history of spontaneous or nocturnal pain, tenderness to percussion or palpation, pathologic mobility, fistulous tract, periodontal ligament (PDL) space widening, internal root resorption, external root resorption, furcal radiolucency/inter-radicular bone destruction and/ or periapical bone destruction and teeth requiring more than 5 minutes to achieve hemostasis during clinical procedure.
Children were divided in to two groups; each child received MTA in right or left side and the other side of the mouth received Propolis. After administration of local anesthesia, the tooth isolated with a rubber dam. All caries was removed and coronal access was gained to expose the pulp chamber. A spoon excavator was used for coronal pulp amputation. One or more sterile cotton pellets moistened with saline was placed over the pulp stumps, and light pressure was applied for 2 - 3 minutes for obtaining hemostasis. Cases that didn't achieve hemostasis were excluded from the study.

At one side of the mouth: One and half gram of standardized propolis extract powder at was mixed with eugenol to form a thick consistency on a clean dry glass slab with a metal spatula.

At the other side of the mouth: MTA paste was prepared as per the manufacturers' instructions to obtain a putty-like consistency. The tested materials were placed on the pulp stumps, and then covered with glass ionomer and stainless-steel crown. All children were recalled for clinical follow up at 3 , 6 and 9 months and for radiographic follow up at 6 and 9 months.

\section{ASSESSMENT}

All cases were clinically assessed for evaluation of pain by asking the guardian at the time of examination. Also, presence or absence of sinus tract was evaluated by one outcome assessors. The assessment was done every 3, 6, and 9 months and all data were recorded in the assessment chart table (1). Oral hygiene instructions were informed to both of the child and the guardian at follow ups. Cases showed failure during the follow up, were recalled and had proper treatment. Radiographic assessment of periapical radiolucency and furcation involvement was done by digital x-rays at 6 and 9 months. The assessment was done by two outcome assessor and Interrater agreement was evaluated by Kappa analysis. 
TABLE (1) : Assessment chart

\begin{tabular}{|c|c|c|c|c|c|c|c|}
\hline & \multicolumn{2}{|c|}{ Base line } & 3 months & \multicolumn{2}{|c|}{6 months } & \multicolumn{2}{|c|}{9 months } \\
\hline \multicolumn{8}{|l|}{ Sinus tract } \\
\hline \multicolumn{8}{|l|}{ Pain } \\
\hline & Assessor 1 & Assessor 2 & & Assessor 1 & Assessor 2 & Assessor 1 & Assessor 2 \\
\hline \multicolumn{8}{|l|}{$\begin{array}{l}\text { Periapical } \\
\text { radiolucency }\end{array}$} \\
\hline $\begin{array}{l}\text { Furcation } \\
\text { Involvement }\end{array}$ & & & & & & & \\
\hline
\end{tabular}

\section{RESULTS}

Numerical data were presented as mean and standard deviation values. Categorical data were presented as frequencies (n) and percentages (\%). Cochran's Q tests followed by multiple pairwise comparisons utilizing McNemar's test with bonferroni correction was used to analyze inter and intragroup comparisons. Cohen's kappa $(x)$ was used to test the inter-examiner reliability. The significance level was set at $\mathrm{P} \leq 0.05$ for all tests. Statistical analysis was performed with IBM $^{\circledR}$ SPSS $^{* \circledR}$. This split mouth clinical trial was conducted on 28 patients. After 9 months, 3 patients dropped out ( 3 patients dropped out after 3 months and one of them returned after 6 months then dropped out again by the end of the study).
Regarding the post-operative pain, all cases were free of post-operative pain at baseline, 3 and 9 months, while at 6 months, There was one case with pain in the side treated with propolis $(3.85 \%)$. There was no statistical significant difference between different follow-up intervals although one case had pain $(p=1.000)$. Frequencies (n) and percentages $(\%)$ of presence of sinus tract are shown in table (2). Regarding the presence of sinus tract: Frequencies (n) and percentages (\%) of presence of sinus tract are shown in table (3). At Baseline and 3 months: All cases were free of sinus tracts. At 6 months: There was one case with sinus tract in the side treated with propolis $(3.85 \%)$ with no statistically significant difference between both groups $(p=1.000)$. At 9 months: Each group had 1 affected case (4\%).

TABLE (2): Frequencies (n) and percentages (\%) of presence of post-operative pain.

\begin{tabular}{|c|c|c|c|c|c|c|}
\hline \multirow{2}{*}{\multicolumn{2}{|c|}{ Pain }} & \multicolumn{2}{|c|}{ MTA } & \multicolumn{2}{|c|}{ Propolis } & \multirow{2}{*}{ P-value } \\
\hline & & \multirow{2}{*}{$\begin{array}{c}\% \\
100 \% \\
\end{array}$} & \multirow{2}{*}{$\begin{array}{l}\text { (n) } \\
\text { (28) }\end{array}$} & \multirow{2}{*}{$\begin{array}{c}\% \\
100 \%\end{array}$} & \multirow{2}{*}{$\begin{array}{l}\text { (n) } \\
(28)\end{array}$} & \\
\hline Baseline & No & & & & & \\
\hline$(\mathrm{n}=28)$ & Yes & $0 \%$ & (0) & $0 \%$ & (0) & \\
\hline \multirow{2}{*}{$\begin{array}{l}3 \text { months } \\
(n=25)\end{array}$} & No & $100 \%$ & (25) & $100 \%$ & (25) & \multirow{2}{*}{------ } \\
\hline & Yes & $0 \%$ & (0) & $0 \%$ & (0) & \\
\hline \multirow{2}{*}{$\begin{array}{l}6 \text { months } \\
(n=26)\end{array}$} & No & $100 \%$ & (26) & $96.15 \%$ & (25) & \multirow{2}{*}{$1.000 \mathrm{~ns}$} \\
\hline & Yes & $0 \%$ & (0) & $3.85 \%$ & (1) & \\
\hline \multirow{2}{*}{$\begin{array}{l}9 \text { months } \\
(n=25)\end{array}$} & No & $100 \%$ & (25) & $100 \%$ & (25) & \multirow{2}{*}{------ } \\
\hline & Yes & $0 \%$ & (0) & $0 \%$ & (0) & \\
\hline \multicolumn{2}{|l|}{ p-value } & \multicolumn{2}{|c|}{------ } & \multicolumn{2}{|c|}{$1.000 \mathrm{~ns}$} & \\
\hline
\end{tabular}


Regarding the periapical radiolucency: Frequencies (n) and percentages (\%) of periapical radiolucency presence are shown in table (4). There was an excellent agreement between both outcome accessors $(\mathrm{k}=0.930)$ which was statistically significant $(p<0.001)$. At baseline: In all cases, no periapical radiolucency was observed in both sides. At 6 months: Periapical radiolucency was found in 3 cases $(11.54 \%)$ treated with MTA, while it was found in 4 cases (15.38\%) treated with propolis. There was no statistically significant difference between both groups ( $p=1.000)$. At 9 months: Periapical radiolucency was found in 4 cases (16\%) in the side treated with MTA, while it was found in 6 cases $(24 \%)$ in the side treated with propolis and there was no statistically significant difference between both groups $(p=0.687)$.

TABLE (3): Frequencies (n) and percentages (\%) of the presence of sinus tract

\begin{tabular}{|c|c|c|c|c|c|c|}
\hline \multirow{2}{*}{\multicolumn{2}{|c|}{ Sinus tract }} & \multicolumn{2}{|c|}{ MTA } & \multicolumn{2}{|c|}{ Propolis } & P-value \\
\hline & & \multirow{2}{*}{$\begin{array}{c}\% \\
100 \% \\
\end{array}$} & \multirow{2}{*}{$\begin{array}{l}\text { (n) } \\
(28)\end{array}$} & \multirow{2}{*}{$\begin{array}{c}\% \\
100 \% \\
\end{array}$} & & \\
\hline Baseline & No & & & & $\begin{array}{l}\text { (n) } \\
(28)\end{array}$ & \\
\hline$(n=28)$ & Yes & $0 \%$ & (0) & $0 \%$ & (0) & \\
\hline \multirow{2}{*}{$\begin{array}{c}3 \text { months } \\
(n=25)\end{array}$} & No & $100 \%$ & (25) & $100 \%$ & (25) & \multirow{2}{*}{------ } \\
\hline & Yes & $0 \%$ & (0) & $0 \%$ & (0) & \\
\hline \multirow{2}{*}{$\begin{array}{c}6 \text { months } \\
(n=26)\end{array}$} & No & $100 \%$ & (26) & $96.15 \%$ & (25) & \multirow{2}{*}{$1.000 \mathrm{~ns}$} \\
\hline & Yes & 0\% & (0) & $3.85 \%$ & (1) & \\
\hline \multirow{2}{*}{$\begin{array}{c}9 \text { months } \\
(n=25)\end{array}$} & No & $96 \%$ & (24) & $96 \%$ & (24) & \multirow{2}{*}{------ } \\
\hline & Yes & $4 \%$ & (1) & $4 \%$ & (1) & \\
\hline \multicolumn{2}{|c|}{ p-value } & \multicolumn{2}{|c|}{$1.000 \mathrm{~ns}$} & \multicolumn{2}{|c|}{$1.000 \mathrm{~ns}$} & \\
\hline
\end{tabular}

TABLE (4): Frequencies (n) and percentages (\%) of presence of periapical radiolucency.

\begin{tabular}{|c|c|c|c|c|c|c|}
\hline \multirow{2}{*}{\multicolumn{2}{|c|}{ Periapical radiolucency }} & \multicolumn{2}{|c|}{ MTA } & \multicolumn{2}{|c|}{ Propolis } & \multirow{3}{*}{$P$-value } \\
\hline & & \multirow{2}{*}{$\begin{array}{c}\% \\
100 \%^{\mathrm{B}}\end{array}$} & \multirow{2}{*}{$\begin{array}{l}(\mathbf{n}) \\
(28)\end{array}$} & \multirow{2}{*}{$\begin{array}{c}\% \\
100 \%^{\mathrm{B}}\end{array}$} & \multirow{2}{*}{$\begin{array}{l}\text { (n) } \\
\text { (28) }\end{array}$} & \\
\hline Baseline & No & & & & & \\
\hline$(\mathbf{n}=\mathbf{2 8})$ & Yes & $0 \%^{\mathrm{B}}$ & (0) & $0 \%^{\mathrm{B}}$ & (0) & \\
\hline \multirow{2}{*}{$\begin{array}{l}6 \text { months } \\
(n=26)\end{array}$} & No & $88.46 \%$ & (23) & $84.62 \%$ & (22) & \multirow{2}{*}{$1.000 \mathrm{~ns}$} \\
\hline & Yes & $11.54 \%$ & (3) & $15.38 \%$ & (4) & \\
\hline \multirow{2}{*}{$\begin{array}{l}9 \text { months } \\
(n=25)\end{array}$} & No & $84 \%^{\mathrm{A}}$ & (21) & $76 \% \%^{A}$ & (19) & \multirow{2}{*}{$0.687 \mathrm{~ns}$} \\
\hline & Yes & $16 \%^{\mathrm{A}}$ & (4) & $24 \%^{\mathrm{A}}$ & (6) & \\
\hline \multicolumn{2}{|l|}{ p-value } & \multicolumn{2}{|c|}{$0.039 *$} & \multicolumn{2}{|c|}{$0.009 *$} & \\
\hline
\end{tabular}


Regarding the furcation involvement: Frequencies (n) and percentages (\%) of furcation involvement presence as shown in table (5). There was a good agreement between both outcome accessors $(\mathrm{k}=0.771)$ which was statistically significant $(p<0.001)$. At Baseline: In all cases, no furcation involvement was observed in both sides. At 6 months: Furcation involvement was found in 2 cases $(7.69 \%)$ in the side treated with MTA, while it was found in 6 cases $(23.08 \%)$ in the side treated with propolis and there was no statistically significant difference between both groups $(p=0.219)$. At 9 months: Furcation involvement was found in 2 cases $(8 \%)$ in the side treated with MTA, while it was found in 6 cases $(24 \%)$ in the side treated with propolis and there was no statistically significant difference between both groups $(p=0.219)$.

TABLE (5): Frequencies (n) and percentages (\%) the presence of furcation involvement.

\begin{tabular}{|c|c|c|c|c|c|c|}
\hline \multirow{2}{*}{\multicolumn{2}{|c|}{ Furcation involvement }} & \multicolumn{2}{|c|}{ MTA } & \multicolumn{2}{|c|}{ Propolis } & \multirow{3}{*}{ p-value } \\
\hline & & \multirow{2}{*}{$\begin{array}{c}\% \\
100 \%\end{array}$} & \multirow{2}{*}{$\begin{array}{l}(\mathbf{n}) \\
(28)\end{array}$} & \multirow{2}{*}{$\frac{\%}{100 \%^{B}}$} & \multirow{2}{*}{$\begin{array}{l}\text { (n) } \\
(28)\end{array}$} & \\
\hline Baseline & No & & & & & \\
\hline$(\mathbf{n}=28)$ & Yes & $0 \%$ & (0) & $0 \%{ }^{\mathrm{B}}$ & (0) & \\
\hline \multirow{2}{*}{$\begin{array}{c}6 \text { months } \\
(n=26)\end{array}$} & No & $92.31 \%$ & (24) & $76.92 \%{ }^{A}$ & (20) & \multirow{2}{*}{$0.219 \mathrm{~ns}$} \\
\hline & Yes & $7.69 \%$ & $(2)$ & $23.08 \%{ }^{\mathrm{A}}$ & (6) & \\
\hline \multirow{2}{*}{$\begin{array}{c}9 \text { months } \\
(n=25)\end{array}$} & No & $92 \%$ & (23) & $76 \%{ }^{A}$ & (19) & \multirow{2}{*}{$0.219 \mathrm{~ns}$} \\
\hline & Yes & $8 \%$ & $(2)$ & $24 \%{ }^{A}$ & (6) & \\
\hline \multicolumn{2}{|c|}{ p-value } & \multicolumn{2}{|c|}{$0.135 n s$} & \multicolumn{2}{|c|}{$0.002 *$} & \\
\hline
\end{tabular}

\section{CLINICAL CASE (1):}

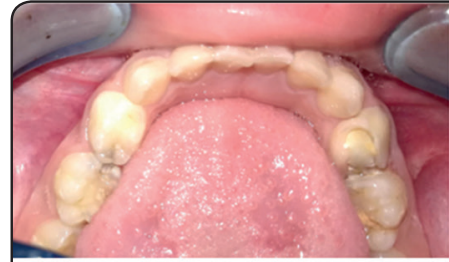

(A) Preoperative

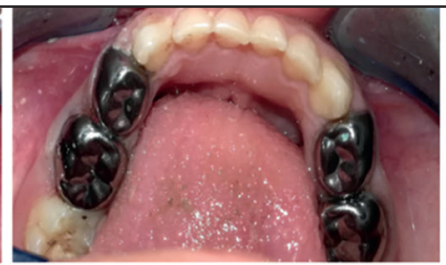

(B) Immediate postoperative

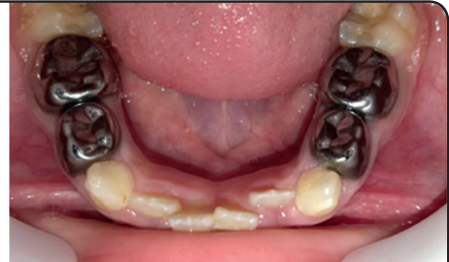

(C) 3 months follow up

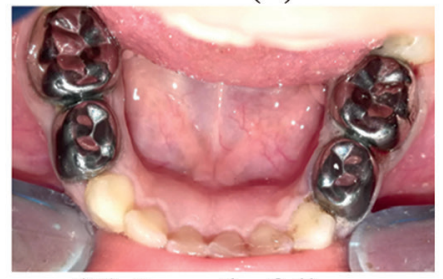

(D) 6 months follow up

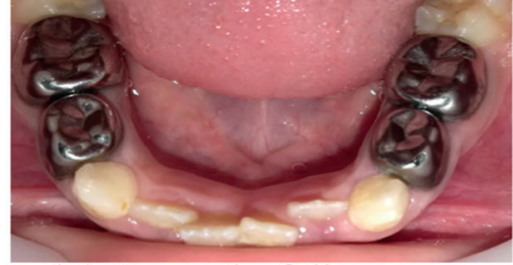

(E) 9 months follow up

Fig. (1) Clinical photographs of a 5 years old child with carious lower right and left second primary molars, (A) preoperative photograph (B) immediate post-operative photographs after pulpotomy and st.st. crown, (C),(D),(E) photographs with successful clinical follow up at 3,6,and 9 months respectively with no evidence of sinus tract . 


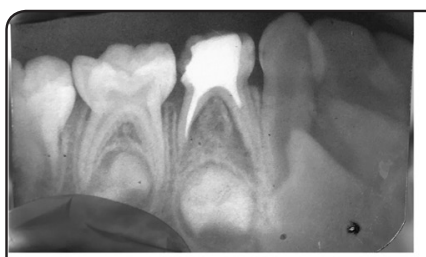

(A) Preoperative

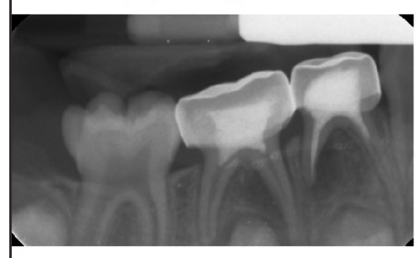

(C) 6 months follow up

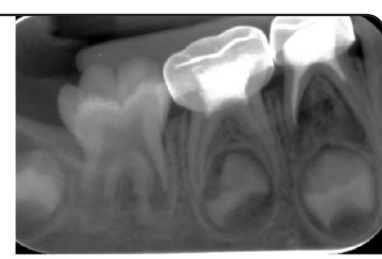

(B) Immediate postoperative

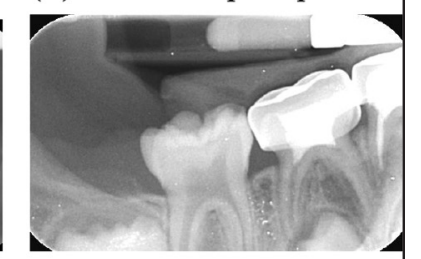

(D) 9 months follow up

Figure (2) Periapical radiographs of MTA side for the same child in different follow periods. (A)Periapical x-ray of lower carious right primary second molar, (B) immediate postoperative digital x-ray after MTA pulpotomy. (C) and (D) radiographic follow up at 6 and 9 months respectively with no evidence of periapical radiolucency or furcation involvement.
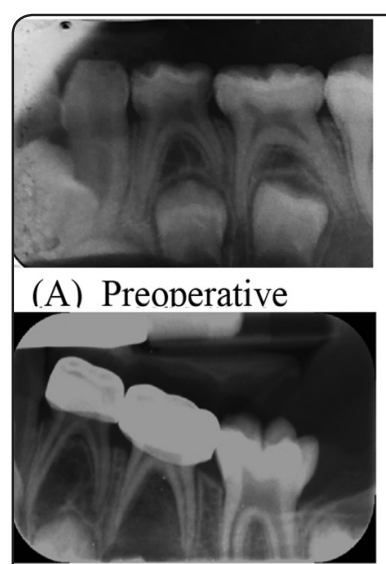

(C) At 6 months follow up

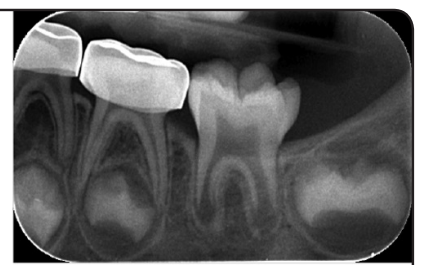

(B) Immediate postoperative

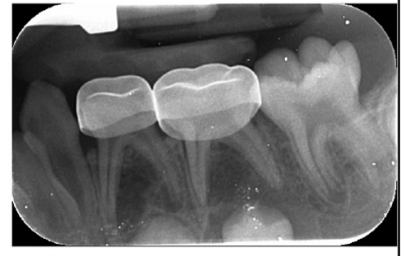

(D) At 9 months follow up

Figure (3) Periapical radiographs of propolis side for the same child (A) periapical x-ray of lower carious left primary second molar, (B) immediate postoperative digital x-ray after propolis pulpotomy. (C) and (D) radiographic follow up at 6 and 9 months respectively with no evidence of periapical radiolucency or furcation involvement.

\section{CLINICAL CASE (2)}

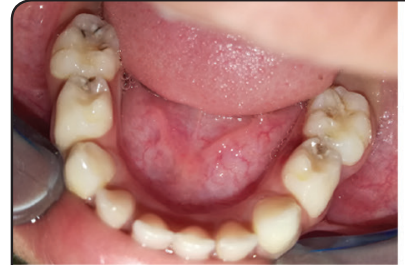

(A)Preoperative

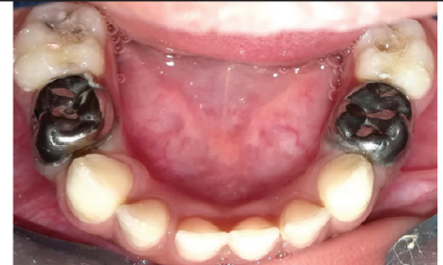

(B) Immediate postoperative

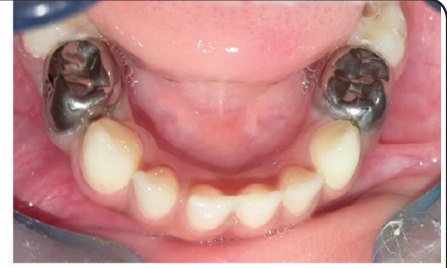

(C) 3 months follow up

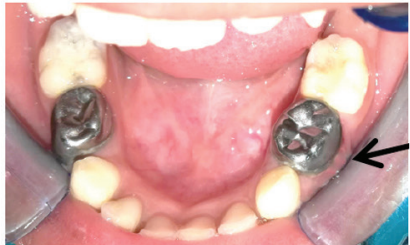

(D) 6 months follow up

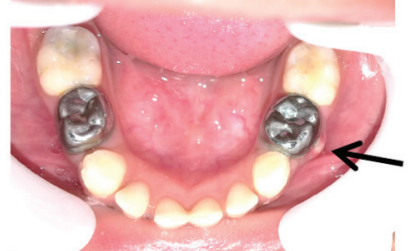

(E) 9 months follow up

Figure (4) Clinical photographs for a 6 years old child with carious lower right and left primary molars showing clinical failure, (A) preoperative photograph (B) immediate photo after pulpotomy and st.st crown,(C),(D),(E) clinical follow up at 3,6,and 9 month respectively with presence of sinus tract at 6 and 9 months. 


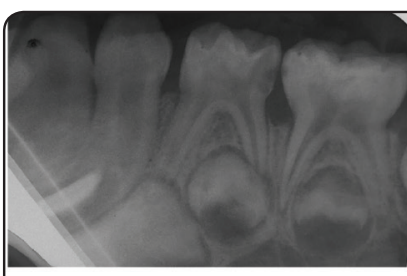

(A) Preoperative

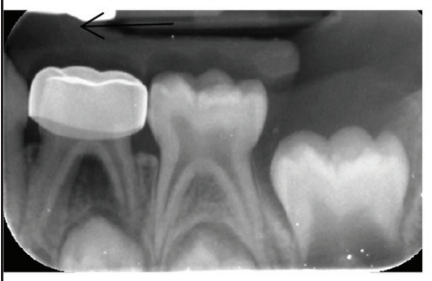

(C) At 6 months follow up

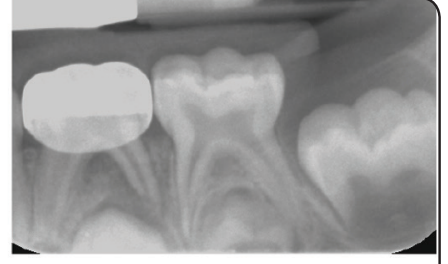

(B) IImmediate postoperative

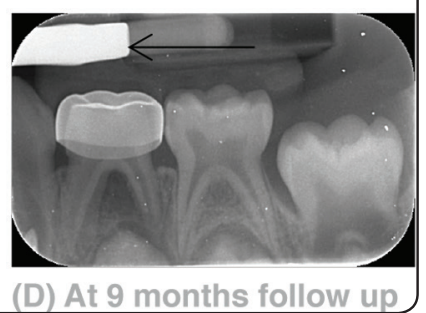

Fig. (5) radiographs of propolis side for the same patient which shows radiographic failure (A) periapical $\mathrm{x}$-ray of lower carious left primary first molar, (B) immediate postoperative digital $\mathrm{x}$-ray after propolis pulpotomy. (C) And (D), radiographic follows up at 6 and 9 months respectively with presence of furcation involvement.

\section{DISCUSSION}

This split mouth clinical trial was conducted on 28 patients. The split-mouth design used in some clinical trials make a randomization scheme on site level where two treatments are randomly assigned to sites of one of the two halves of the mouth. The main purpose of the split-mouth design is to remove all components related to differences between subjects from the treatment comparisons, by making withinpatient comparisons, rather than between-patient comparisons ${ }^{[13]}$. A careful diagnosis was done before this treatment to ensure good selection criteria. In the present study, preoperative radiographic examination was done by conventional periapical radiography to ensure inclusion and exclusion criteria of the selected cases, it fulfilled the purpose of diagnosis according to ${ }^{[14]}$.

Paralleling technique on the same radiographic unit with the same exposure parameters $(0.06 \&$ $70 \mathrm{kv}$ ) using individual bite blocks of acrylic resin attached to the individual XCP (Extension cone paralleling) acrylic index that was prepared for each patient by registering the bite and was placed around the XCP plastic tip for standardization of the radiographs. Therefore, constant relationship between either the object and radiographic image plate or the object and the x-ray source is obtained. Thus, consistent comparison of the standardized radiographs would be possible ${ }^{[15]}$.
The pulpotomy material in the intervention group was Propolis, which has shown significant potential for pulpal healing, repair, and also no cytotoxic effects on cells of pulp or PDL ${ }^{[16]}$. Propolis is found to have antiseptic, antibacterial, astringent, spasmolytic, anti-inflammatory, anesthetic, antioxidant, antifungal, antiulcer, anticancer, and immunomodulatory effects. It has been used in several applications, which include ointments and creams used in wound healing, treatment of burns, skin problems, and ulcer $^{[12]}$. Children were selected in age range between 5-8 years each having at least one carious primary molar at each side. Each child received MTA in right or left side and the other side of the mouth received Propolis according to allocated group.

In this study, rubber dam isolation was done before access opening to avoid any bacterial contamination. According to study done by Keys and Carson ${ }^{[17]}$, showed that rubber dam usage may increase the survival time of any restoration and decrease the rate of failure. Prevention of micro-leakage is an important factor contributing to the success of any vital pulp therapy procedure. Nowicka et al. ${ }^{[18]}$ found that MTA has excellent sealing properties and potential to prevent micro-leakage. But, no evidence of sealing ability of Propolis was found. Only, Park et al. ${ }^{[19]}$ found that Propolis helps in collagen synthesis and wound healing. Croll and Killian, ${ }^{[20]}$ recommended the use stainless steel crowns for 
full coverage of pulpotomized teeth based on the assumption that there is less leakage in crowned teeth than those restored with amalgam.

The outcomes in term of success or failure treatment were determined through: clinical evaluation and radiographic evaluation. In the present study, clinical follow up was done 3 times at 3,6 and 9 months. Clinical follow up included post-operative pain, presence of sinus tract. Regarding post-operative pain, all cases were free of pain along the follow up period except one case in propolis group showed pain after 6 months then disappeared at 9 months. There was no statistically significant difference between different follow-up intervals. These results came in accordance with the study conducted by Kusum et al. ${ }^{[1]}$, in which pain was not noticed during follow up periods. These occurred due to the anti-inflammatory property of propolis which inhibits prostaglandin synthesis, stimulates cell immunity, increases the reparative capacity, and causes less tissue irritation provided by the presence of flavonoids, aromatic acids, and esters ${ }^{[10]}$.

Regarding the presence of sinus tract, at 3 months: all cases were free of sinus tracts, at 6 months: one case had sinus tract in the side treated with Propolis. At 9 months in the same case, sinus tract remained in the same side of propolis and appeared in in the side of MTA. The clinical findings in our study came in accordance to Alolo et al. ${ }^{[11]}$ who conducted a clinical study on primary molars to compare the natural extracts in vital pulpotomy of primary teeth. The good clinical pulp response has been found with the use of propolis as due to its low irritating potential, and induction of healing process in both epithelial and pulp tissue with formation of collagen ${ }^{[12]}$.

Regarding the periapical radiolucency and furcation involvement, periapical radiolucency in both groups was noticed at 6 months, and increased at 9 months. Furcation involvement appeared at 6 months in both groups with no change at 9 months.
The number of cases in propolis group with furcation involvement and periapical radiolucency was more than in MTA group. This study came in accordance with the study of Hugar ${ }^{[12]}$ who noticed by the end of 6 months, one tooth in the propolis group had signs of radiographic failure but was clinically free of symptoms.

\section{CONCLUSIONS}

On the basis of the results of the present study, it can be concluded that: The clinical outcome of propolis is comparable to that of MTA at both 6 and 9 months follow up period. However, MTA shows better clinical outcomes than Propolis. Postoperative pain appeared in propolis group. Sinus tract appeared in both MTA and propolis groups at 9 months follow up. Propolis showed more radiographic failure than MTA.

\section{RECOMMENDATIONS}

Upon the results we recommend that, with the combination of the traditional regenerative materials as MTA and the advantage of natural materials as propolis, more therapeutic materials are underway for finding the next gold standard material in pediatric endodontics. MTA and Propolis may be used as a pulpotomy material. Further studies are needed with larger sample size and longer follow up periods.

\section{REFERENCES}

1. Kusum, B., Rakesh, K., Richa, K., Caicedo, R., Abbott, P., Alongi, D., Alarcon, M., Magnusson, B., Ranly, D., Eidelman, E., Holan, G., Fuks, R., Torabinejad, M., Chivian, M., Antúnez, L., Waterhouse, P., Nunn, J. \& Whitworth, J. (2015) Clinical and radiographical evaluation of mineral trioxide aggregate, biodentine and propolis as pulpotomy medicaments in primary teeth. Restorative Dentistry \& Endodontics Journal, 40 (4), p.276.

2. Holan, Gideon, Eidelman, Eliezer, Fuks, (2005) Longterm Evaluation of Pulpotomy in Primary Molars Using Mineral trioxide aggregate or formocresol. Pediatric Dentistry journal, Volume 27, Number 2, March/April 2005, pp. 129-136(8). 
3. Glickman, G.N. \& Koch, K.A. (2000) 21st-century endodontics. Journal of the American Dental Association, 131 (6 SUPPL.), pp.39S-46S.

4. Schwartz, R.S., Mauger, M., Clement, D.J. \& Walker, W.A. (1999) Mineral trioxide aggregate: A new material for endodontics. Journal of the American Dental Association, 130 (7), pp.967-975.Cited in Shaghaghian, S., Abolvardi, M. \& Akhlaghian, M. (2018) Factors Affecting Dental Caries of Preschool Children in Shiraz, Journal of dentistry (Shiraz, Iran), 19 (2), pp.100-108.

5. Shafie, L., Barghi, H., Parirokh, M., Ebrahimnejad, H., Nakhae, N. \& Esmaili, S. (2017) Postoperative pain following pulpotomy of primary molars with two biomaterials: A randomized split mouth clinical trial. Iranian Endodontic Journal, 12 (1), pp.10-14.

6. Patidar, S., Kalra, N., Khatri, A. \& Tyagi, R. (2017) Clinical and radiographic comparison of platelet-rich fibrin and mineral trioxide aggregate as pulpotomy agents in primary molars. Journal of Indian Society of Pedodontics and Preventive Dentistry, 35 (4), pp.367.

7. Junqueira, M.A., Cunha, N.N.O., Caixeta, F.F., Marques, N.C.T., Oliveira, T.M., Moretti, A.B. da S., Cosme-Silva, L. \& Sakai, V.T. (2018) Clinical, radiographic and histological evaluation of primary teeth pulpotomy using MTA and ferric sulfate. Brazilian Dental Journal, 29 (2), pp.159-165.

8. Monteiro Bramante, C., Demarchi, A.C.C.O., de Moraes, I.G., Bernadineli, N., Garcia, R.B., Spångberg, L.S.W. \& Duarte, M.A.H. (2008) Presence of arsenic in different types of MTA and white and gray Portland cement. Oral Surgery, Oral Medicine, Oral Pathology, Oral Radiology and Endodontology Journal, 106 (6), pp.909-913.

9. Parolia, A., Kundabala, M., Rao, N., Acharya, S., Agrawal, P., Mohan, M. \& Thomas, M. (2010) A comparative histological analysis of human pulp following direct pulp capping with Propolis, mineral trioxide aggregate and Dycal. Australian Dental Journal, 55 (1), pp.59-64.

10. Ozorio, J.E.V., De Oliveira E Silva Carvalho, L.F., De Oliveira, D.A., De Sousa-Neto, M.D. \& Da Cruz Perez, D.E. (2010) Standardized propolis extract and calcium hydroxide as pulpotomy agents in primary pig teeth. Journal of Dentistry for Children, 79 (2), pp.53-58.

11. Alolo, H., El-sayed, M. \& Taha, S. (2016) Clinical and radiographical evaluation of propolis and thymus vulgaris extracts compared with formocresol pulpotomy in human primary molars. British Dental Journal BDJ 16005;pp.1-6.
12. Hugar, S.M. (2017) Comparative Evaluation of Clinical and Radiographic Success of Formocresol , Propolis , Turmeric Gel , and Calcium Hydroxide on Pulpotomized Primary Molars : A Preliminary Study. International Journal of Clinical Pediatric Dentistry, 10(1), pp.18-23.

13. Zanatta, Rayssa Ferreira, Silva, Tânia Mara da, Esper, Maria Ângela Lacerda Rangel, Bresciani, Eduardo, Caneppele, Taciana Marco Ferraz, Gonçalves, Sergio Eduardo de Paiva (2017) Guidelines for conducting split-mouth clinical studies in restorative dentistry, Brazilian Dental Science, 20 (2), pp.29-37

14. Shah, N. (2014) Recent advances in imaging technologies in dentistry. World Journal of Radiology, 6 (10), p.794.

15. Messias, A., Rocha, Salomao, Reis, R., Tondela, P., Rocha, Salomão, Nicolau, P. \& Guerra, F. (2013) Acrylic Customized X-Ray Positioning Stent for Prospective Bone Level Analysis in Long-Term Clinical Implant Studies. Article in Open Journal of Radiology, 3, pp.136-142.

16. Scheller, S., Ilewicz, L., Luciak, M., Skrobidurska, D., Stojko, A. \& Matuga, W. (1978) Biological properties and clinical application of propolis. IX. Experimental observation on the influence of ethanol extract of propolis (EEP) on dental pulp regeneration. Arzneimittel-Forschung, 28 (2), pp.289-91.Cited in Balata, G.F., Abdelhady, M.I.S., Mahmoud, G.M., Matar, M.A. \& Abd El-Latif, A.N. (2017) Formulation of Saudi Propolis into Biodegradable Chitosan Chips for Vital Pulpotomy. Current Drug Delivery Journal, 15 (1), pp.97-109.

17. Keys, W. \& Carson, S.J. (2017) Rubber dam may increase the survival time of dental restorations. Evidence-Based Dentistry Journal, 18 (1), pp.19-20.

18. Nowicka, A., Lipski, M., Parafiniuk, M., Sporniak-Tutak, K., Lichota, D., Kosierkiewicz, A., Kaczmarek, W. \& Buczkowska-Radlińska, J. (2013) Response of human dental pulp capped with biodentine and mineral trioxide aggregate. Journal of Endodontics, 39 (6), pp.743-747.

19. Park, Y.K., Alencar, S.M. \& Aguiar, C.L. (2002) Botanical origin and chemical composition of Brazilian propolis. Journal of agricultural and food chemistry, 50 (9), pp.2502-6.

20. Croll, T.P. \& Killian, C.M. (2002) Zinc oxide-eugenol pulpotomy and stainless steel crown restoration of a primary molar. Quintessence International Journal , 23 (6), pp.383-8. 